\title{
A THREE-PRONG STRATEGIC APPROACH TO SUCCESSFUL DISTANCE LEARNING DELIVERY
}

Carol Scarafiotti

Dean of Instruction

Rio Salado College

2323 W. $14^{\text {th }}$ St.

Tempe, AZ 85281-6950

(480) 517-8135

Fax: (480) 517-8149

carol.scarafiotti@riomail.maricopa.edu

\begin{abstract}
Rio Salado College, headquartered in Tempe, Arizona, is nationally recognized as a role model for innovation and excellence in online education and as the "college of choice" for adults who balance their studies with work and family. One of the ten Maricopa Community Colleges, Rio Salado College has had a distance learning program since its inception in 1978. This paper describes a systems approach to the growth of successful online programs, using data for continuous improvement.
\end{abstract}

\section{KEYWORDS}

Learning Effectiveness, Cost Effectiveness, Continuous Quality Improvement, Scalability, Faculty Satisfaction

\section{INTRODUCTION}

Rio Salado College, headquartered in Tempe, Arizona, is nationally recognized as a role model for innovation and excellence in online education and as the "college of choice" for adults who balance their studies with work and family. One of the ten Maricopa Community Colleges, Rio Salado College has had a distance learning program since its inception in 1978.

While Rio Salado College's early distance program maintained a relatively small but steady enrollment through its correspondence and telecourses, its enrollments began to surge in 1996 with the addition of Internet as a delivery mode. That is, in 1995 approximately 6,000 students enrolled in the distancelearning program annually generating 500 full-time enrollment equivalents (FTEE) or 10 percent of the total college FTEE in credit courses. In comparison, by the end of 2003 over 22,000 individual students will enroll in the college's distance learning program consisting mainly of fully online credit courses, generating 4,000 FTEE or approximately 48 percent of the college's total FTEE. Figure 1 illustrates the extraordinary FTEE growth of Rio's distance learning program over the last eight years. 
Figure 1 - Rio Salado's Distance Learning Program Growth

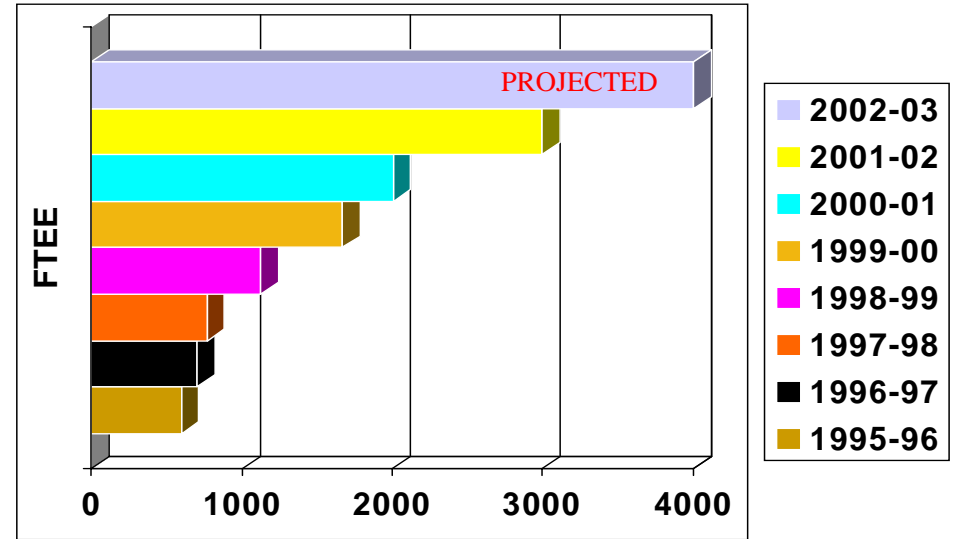

The September 2002 Eduventure Report "Distance at a Tipping Point" [1] estimates that the fully online distance learning market is growing in excess of 40 percent annually and that fully online enrollments will represent 4.2 percent of the total post secondary enrollments in 2003. With the majority of Rio's distance program enrollments coming from fully online courses, Rio Salado's distance learning enrollment growth typifies and in some respects exceeds Eduventure's predictions.

Rio Salado's significant growth in distance learning relates partially to its good timing, as it was an early adopter of the Internet as a delivery mode, but more importantly its success emanates from what Built to Last [2] author, James Collins, refers to as preserving core ideology while "stimulating progress." Rio's core ideology is illustrated by its Vision, Pride Factors, and Core Values.

Vision: Through living our values, Rio Salado College creates a climate of high expectations for the success of our students, customers and employees.

Pride Factors: We take great pride in providing programs and services that are characterized by: Quality, Convenience, Timeliness, and Accuracy

Core Values: We are unalterably committed to demonstrating the following core organizational values: Learning, Customer Focus, Innovation, Assessment/Continuous Improvement, Teamwork, Professionalism, and Diversity

Thus, this article concentrates on Rio's deliberate approach used to stimulate the growth and success of its distance learning program. Its three-prong strategy includes: 1) making online learning central to the mission of the college through a systems approach, 2) establishing Rio's online learning brand with its customers, and 3) focusing college efforts and resources on effective learning outcomes and student and faculty satisfaction.

\section{A. Strategy 1: Main Mission/Systems Approach}

Although Rio Salado offers a typical comprehensive community college curriculum including transfer and workforce development programs, in 1995 it adopted a mission which focused the college's expertise in three areas: customized and unique programs and partnerships, accelerated formats, and distance delivery.

\section{College Mission}

As an institution of higher education placing high value on student learning, Rio Salado College creates convenient, high-quality learning opportunities for diverse populations. We specialize in customized, unique programs and partnerships, accelerated formats and distance delivery. In all that we do, we 
pursue continuous improvement and innovation, and we challenge the limits of tradition.

An example of what it means operationally for distance learning to be central to the mission resides in an organizational change made in 1996 in which Rio Salado's self-contained distance learning department was dismantled and replaced with a college-wide systems approach to distance learning. The approach is modeled after Russell Ackoff's [3] view of system performance in which the system depends not only on the performance of each part but on how successfully each part interacts with other parts to "affect the performance of the whole." Figure 2 illustrates the college's distance learning system which promotes organizational learning through the sharing of data, information, and insight across the college while providing support to distance learning faculty and students.

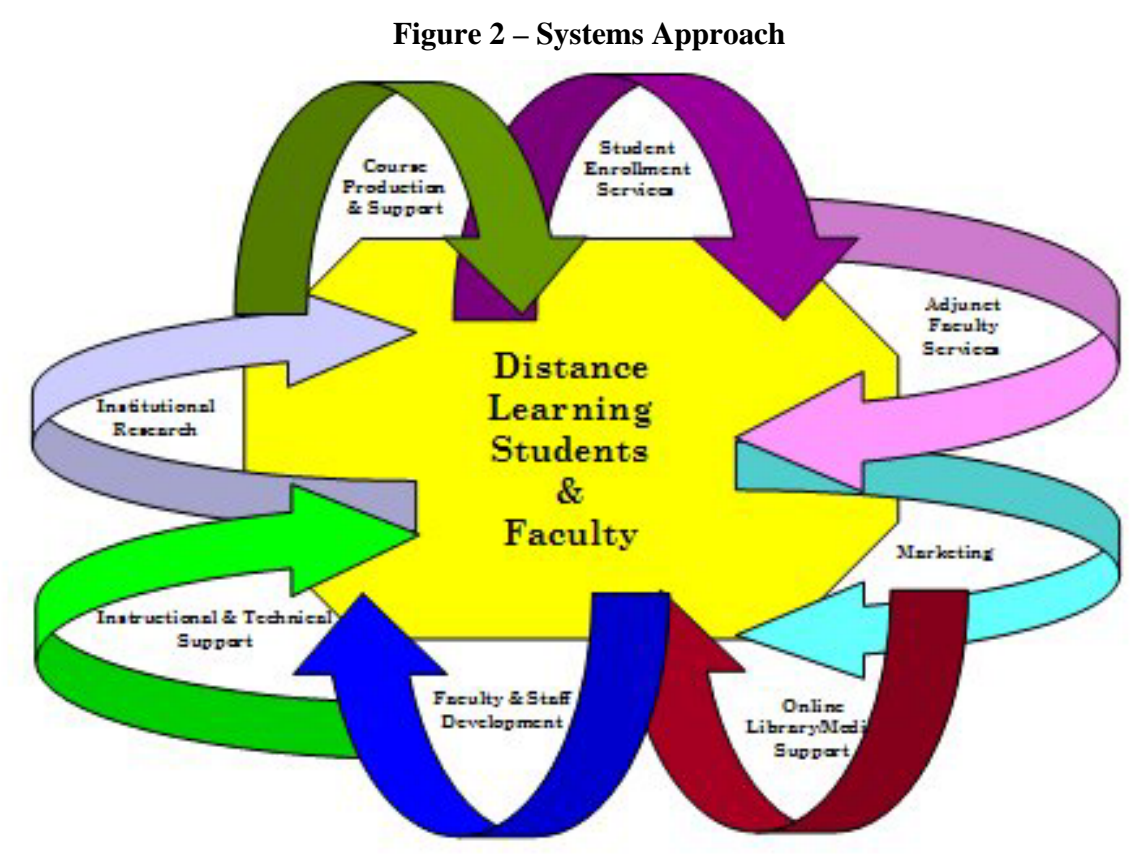

Another outcome of distance learning as a main mission area is the college's commitment to capacity development and resource allocation. The college invests significant resources in its technology and service infrastructure to ensure the scalability required by its growth. For instance, the college's Information Technology department has grown from three employees in 1991 to 27 in 2003.

\section{B. Strategy 2: The Rio Branding of online learning}

Rio has two types of online learning customers, the individual student and organizations or institutions that send students to Rio's online program; both types of customers are attracted to Rio's particular approach to or brand of online education. The typical individual distance learning student is a female 25 years or older who is a savvy consumer and strapped for time, as she manages a family, works full-time, and is enrolled in 3-6 semester credit hours. A case in point of an institutional customer is the US Army and its eArmy U program which selected Rio as a provider of online programs. Well over 3,600 army personnel throughout the world enroll in Rio's online courses and programs, making Rio the third largest provider of online education to the Army. Rio regularly surveys its customers seeking to understand what they want and need from the distance-learning program, and it is these responses that have helped to shape Rio's brand of online learning, which is characterized as follows: 
Choice and Access: Over 320 unique courses are available to students through Rio's distance learning program. Of these, 220 courses are delivered through the Internet with the remaining courses delivered as print based or mixed media, a combination of print and tape or CD. Course offerings include large numbers of general education courses serving students intending to transfer to the university as well as courses that prepare students for the workplace such as software applications, marketing, or education. These online courses apply to 12 associate degrees, 21 certificate programs, and two post baccalaureate pathways. Among the newest of the program areas available online are Post-Baccalaureate Teacher Preparation, Clinical Dental Assisting, and Nursing. The many choices of available courses are further enhanced by the fact that ninety percent of Rio's online courses begin every two weeks. In fact, Rio's customers rate access, as provided by these rolling starts, as the most important aspect of its brand.

High Quality Anytime, Anyplace Learning Design: Early on, the college leadership decided that to ensure the quality of the instructional design and control resource allocation, the college would adopt a "one course, multiple sections" model. In this model the college allocates significant resources to develop the complete master course, including assessments as well as content and assignments, and numerous sections of the master course are taught by various faculty members. This model makes certain that all students are exposed to consistent course content and provides the college with sufficient learning outcomes data for use in course revision. Also, students can anticipate that all Rio online learning courses contain navigation that is functionally predictable and consistent.

All online learning courses at Rio, by design, are delivered asynchronously and do not require set meeting times for students and faculty members, thus facilitating flexible and convenient learning. While most courses require 14 weeks to complete, with permission from an instructor students can finish the course in an accelerated time frame.

Organizational Responsiveness and Personalized Support: The ability to provide independent learners with timely answers to a variety of questions is critical to the effectiveness of Rio's online learning program. However, while each discipline area has established expectations for faculty response time to student questions and assignments, students' demands for responsiveness goes well beyond what an individual faculty member can reasonably provide. Information derived from faculty focus groups indicated that many of the questions asked of faculty members are peripherally associated with learning the course content and can be answered by someone other than the faculty member teaching the course. Therefore, the college established two helpdesks, which respond to students' needs. The Technology Helpdesk, available 7 days a week, 14 hours a day, 360 days a year, provides technology assistance to students. It was from the Technology Helpdesk call data that the college noted a need for help related to the questions about the course such as when and where to take a test. Thus, the college established an Instructional Helpdesk available 6 days a week from 8:00 am-8:00pm Monday through Thursday and 8:00am-5:00 pm Friday and Saturday. The Instructional Help Desk personnel are adjunct faculty members who can answer student questions about the course structure, who conduct in-person and virtual online learning orientations, and who also serve as liaisons between students and faculty. The Instructional Help Desk is also the source of tutoring assistance. Rio Salado College contracts with SMARTHINKING, an online tutoring service, and also has its own "Beep a Tutor" program. In the Beep a Tutor program students in math, language, and science courses can page a tutor who will call back within an hour.

Customized online support services available six days a week: Additional support services are available online and by phone six days a week (Monday through Saturday) including during traditional holiday breaks. These include enrollment services of admission and records, advising, counseling as well as financial aid. Rio's virtual library and reference librarian are available seven days a week. Rio Salado 
outsources its online bookstore function to eFollet.

\section{Strategy 3: A Focus on Effective Learning Outcomes and Student and Faculty Satisfaction}

The college has enacted both a proactive and reactive approach to learning effectiveness in online learning. Proactively, the Rio faculty developers of the master courses, along with course support personnel, have established requirements and guidelines (recommended practices) used in development and production of online courses. For instance, "The Keys to Instruction" is the main standard associated with the instructional design of all of Rio's online learning courses. Developed by the Rio faculty, the "Keys to Instruction" is a template which ensures that the content, assignments, activities and assessments align with course competencies and objectives; that each lesson provides a foundation for new learning by connecting it to previous learning; and that the student becomes actively involved in the lesson, which includes the student summarizing the learning. Also, as a result of a presentation by Dr. David Merrill, noted expert in instructional design and professor at University of Utah, the Rio faculty strengthened their collective position on real world application of course content by developing guidelines that increase real world relevancy in course design. These guidelines ensure that courses include concrete tasks to be learned, that they have adequate examples which demonstrate the task, and that they contain sufficient practice opportunities.

Web technicians who assist the faculty developer to put the course online also follow usability standards which make certain that the course integrates with Rio's distance learning support system; that the course is easily navigated; that there is format consistency throughout the home page, syllabus, lessons and assignments; and that copyright acknowledgments are in place.

From the reactive perspective, once a course is in use, Rio faculty developers collect quantitative and qualitative data from students, adjunct faculty members, and results of course exams and assignments. For example, the "one course, multiple sections" model provides ample learning outcomes data (from common assignments, midterms and finals); these data are used to reveal the course's strengths and problems and ultimately to improve the course. Also, course completion data, another measure of learning effectiveness, are collected annually. Rio's completion rate for online courses averages 75 percent.

Since 1991, the Rio Salado College culture has been heavily invested in continuous improvement and therefore places great value on information about customer satisfaction. The college regularly collects student satisfaction feedback, formally through surveys and focus groups and informally from faculty and other personnel such as helpdesk technicians who communicate directly with students. Recently, the college has been conducting student experience audits in an attempt to understand the online student's experience first hand. That is, the college pays students a small stipend to navigate through courses and complete assignments while being videotaped by a Rio staff member. This videotaped audit enables college personnel to see what students actually experience as they navigate through the online courses and Rio's support network. As a result of these audits, the college is able to continuously improve both the course and its online services.

Feedback from faculty teaching online courses as well as those who develop courses helps determine the level of faculty satisfaction. Adjunct faculty satisfaction is critical to the success of Rio's online program because at Rio Salado College most of the online courses are taught by adjunct faculty members. At Rio Salado College a developed course is provided to the adjunct faculty member who then facilitates and 
assesses the learning. The college conducts annual faculty surveys and focus groups, which reveal important information that is used to improve the adjunct faculty support system. For example, surveys of adjunct faculty members who teach online courses indicate that faculty who like the flexibility of online teaching are the most satisfied. They like teaching a high quality course (already developed) because they can spend their one-on-one time helping students learn. Survey data also indicate that adjunct faculty members want the "back end" of a course system to minimize administrative tasks so they can dedicate their time to teaching. At Rio Salado College, the overall annual turnover rate for online adjunct faculty is a low four percent.

Surveys of faculty who develop online courses indicate that they are very satisfied with the full slate of services that is provided to faculty members who are designing courses. They also indicate that faculty developers prefer concentrating their energy on the instructional design of the course and are pleased to have course production tasks handled by technicians.

\section{CONCLUSION}

Rio Salado College's successful strategy for continued growth in its online learning program includes a mission focused on developing college-wide expertise for online learning, as well as a systems approach to online learning support, a branding of its program characteristics, and a focus on achieving desired learning outcomes along with student and faculty satisfaction - all supplemented with surveys and experience audits, documenting continuous improvement as a regular practice.

\section{ABOUT THE AUTHOR}

Carol Scarafiotti is the Dean of Instruction at Rio Salado College, a community college nationally recognized as a role model for innovation and excellence in online learning. Having led the effort to create a system's approach to distance learning at Rio Salado College, she has firsthand knowledge of what it takes sustain a distance learning program with over 220 unique fully online courses, with registration available every two weeks, with 22,000 students enrolled annually. In 2002 she and Patricia S. Case, also of Rio Salado, received the Sloan C Award for Excellence in Online Access.

She is recognized for her collaborative approaches with faculty in achieving innovative instructional design and support systems and for her expertise in assessment of learning outcomes and development of adjunct faculty support services.

She frequently speaks at conferences about issues related to the online learning culture in higher education.

\section{REFERENCES}

1. Gallagher, Sean. Distance Learning at the Tipping Point. Eduventures Report. September 2002.

2. Collins, James C., and Jerry Porras. Built to Last, New York: Harper Collins Publishers, Inc. 1994.

3. Ackoff, Russel. The Democratic Corporation, New York: Oxford University Press. 1994. 